\title{
……
}

RESEARCH AND EDUCATION

\section{Effect of an experimental silica-nylon reinforcement on the fracture load and flexural strength of bisacrylic interim partial fixed dental prostheses}

\author{
Carolina Souza Almeida, DDS, MSc, ${ }^{a}$ Marina Amaral, DDS, MSc, $\mathrm{PhD},{ }^{\mathrm{b}}$ \\ Fernanda de Cássia Papaiz Gonçalves, DDS, MSc, $\mathrm{PhD}^{\mathrm{C}}$ and \\ Tarcisio José de Arruda Paes-Junior, DDS, MSc, $\mathrm{PhD}^{\mathrm{d}}$
}

Oral rehabilitation with fixed dental prostheses (FDPs) generally requires the use of interim restorations. These restorations must protect the dentin-pulp complex in addition to fulfilling mechanical and esthetic requirements. ${ }^{1}$ This intermediate phase of rehabilitation is useful for adjusting the treatment, correcting failures in initial planning, and seeking the clinical success of the definitive prosthesis. ${ }^{1}$ Although they have limited term application, the restorations must be fabricated carefully so that the main difference between the interim and definitive prosthesis is the material chosen for the restoration.

One material available for interim restorations is bisacrylic resin, which is a relatively new material introduced to provide long-term mechanical stability. ${ }^{2}$ The popularity of bisacrylic resin for interim restorations is a

\begin{abstract}
Statement of the problem. Materials used in the fabrication of interim restorations usually have mechanical properties inferior to those used in definitive prostheses. Various techniques may be used to reinforce these materials.

Purpose. The purpose of this in vitro study was to evaluate the fracture strength of interim partial fixed dental prostheses (FDPs) with and without an experimental silica-nylon reinforcement placed in different orientations (horizontal or vertical) before and after thermocycling and to evaluate the flexural strength of the bisacrylic resin used for fabricating these prostheses.

Material and methods. For fracture strength testing, 72 four-unit interim partial FDPs were fabricated from bisacrylic resin and divided into 3 groups: no reinforcement, horizontal reinforcement, and vertical reinforcement. Half of the specimens from each group were thermocycled before testing $\left(1000\right.$ cycles between $5^{\circ} \mathrm{C}$ and $\left.55^{\circ} \mathrm{C}\right)(n=12)$. An increasing load was applied to the center of the prosthesis until fracture. The flexural strength of bisacrylic resin reinforced with the experimental mesh was measured by using a 3-point bending test with $25 \times 10.5 \times 3.3 \mathrm{~mm}$ bars of resin, with or without thermocycling. The results were evaluated with analysis of variance and Kaplan-Meier survival analysis $(\alpha=.05)$.
\end{abstract}

Results. The results showed that incorporating the experimental silica-nylon reinforcement in a horizontal orientation provided the highest values of fracture strength for the 4-unit partial FDPs. Reinforcement also enhanced the flexural strength values of bisacrylic resin bars.

Conclusion. Silica-nylon reinforcement is an effective method of increasing the strength of interim restorations. (J Prosthet Dent 2016;115:301-305)

result of its simple fabrication and handling methods, desirable esthetics, ease of polishing, and superior mechanical properties when compared with conventional resins. ${ }^{3,4}$

\footnotetext{
${ }^{a}$ Graduate student, Department of Dental Materials and Prosthodontics, São Paulo State University (UNESP), Institute of Science and Technology, São José dos Campos Dental School, São José dos Campos, Brazil.

${ }^{\mathrm{b}}$ Researcher, Post Graduation Program in Dentistry, University of Taubate (UNITAU), Taubate, Brazil.

cDoctoral student, Department of Dental Materials and Prosthodontics, São Paulo State University (UNESP), Institute of Science and Technology,

São José dos Campos Dental School, São José dos Campos, Brazil.

${ }^{d}$ Associate Professor, Department of Dental Materials and Prosthodontics, São Paulo State University (UNESP), Institute of Science and Technology, São José dos Campos Dental School, São José dos Campos, Brazil.
} 


\section{Clinical Implications}

When interim restorations are required for an extended time, mechanisms should be applied to enhance the mechanical properties of the material used. The application of a silica-nylon reinforcement may be a viable and efficient method of achieving this goal.

Interim restorations may provide several benefits for rehabilitation treatment, but they may also present disadvantages in long-term clinical function; fractures within the materials used are frequently reported. ${ }^{1,5}$ The inclusion of reinforcement materials is one of the methods used to improve their properties. Options for the reinforcement of interim restorations include aramid, glass, polyethylene, or carbon fibers, metal wires, and nylon. ${ }^{6-10}$ The type of material applied, the quality of the bond between the fiber and the matrix, the percentage of added reinforcement material, and the length and orientation of the fibers added must be considered when selecting the appropriate material. ${ }^{11}$

Nylon (polyamide 6.0) is a polyamide with less than $85 \%$ of its amides linked to aromatic rings. It is a synthetic polymer and is used extensively to fabricate fibers because of its durability and resistance. ${ }^{11}$ The use of this material to reinforce composite resins has been investigated, with results showing efficiency in the enhancement of their flexural strength. ${ }^{11-15}$ Recently, an experimental silica-nylon grid with promising results for the reinforcement of acrylic resin prostheses has been developed (ICT/UNESP, São José dos Campos, Patent number: BR1020120281198). This material is composed of nylon 6.0 (polyamide 6.0) and silanized silica ( $0.5 \%$ volume), which are injected together into a matrix to create a mesh, blending the favorable properties of both nylon and silica. Silica allows the mesh to chemically bond with polymeric materials. In addition, the mesh is manufactured in a single body, optimizing stress distribution when loads are applied (unpublished results). The purpose of this study was to evaluate the effects of the addition and orientation of this silicanylon reinforcement on the fracture load and flexural strength of bisacrylic resin in the fabrication of interim restorations.

\section{MATERIAL AND METHODS}

The fracture load was measured in 72 four-unit interim FDPs made of bisacrylic resin (Structur 2SC; VOCO). A metallic matrix with 2 metal abutments simulating the preparation of a maxillary canine $(5 \mathrm{~mm}$ in height, $2 \mathrm{~mm}$ in radius, and 6 degrees of wall convergence) and a first molar $(5 \mathrm{~mm}$ in height, $4 \mathrm{~mm}$ in radius, and 6 degrees of wall convergence), $18.3 \mathrm{~mm}$ apart from each other (center-to-center), was used to fabricate the FDPs.

The reinforcement material was cut to a length that would cover the abutment-to-abutment distance (approximately $19 \mathrm{~mm}$ ) and was stabilized with composite resin (Z250; 3M ESPE). The reinforcement was represented by a strip $(19 \times 1 \times 0.3 \mathrm{~mm})$, with the $1 \mathrm{~mm}$ dimension positioned in either a horizontal or vertical orientation. In the horizontal orientation, the reinforcement had a width of $1 \mathrm{~mm}$ and a height of $0.3 \mathrm{~mm}$. In the vertical orientation, the reinforcement had a width of 0.3 $\mathrm{mm}$ and a height of $1 \mathrm{~mm}$. A silicone matrix was fabricated through waxing of the restorations on the abutments and making an impression of the wax with silicone (Zetalabor Oranwash/Indurent Gel; Zhermack). The matrix was then filled with bisacrylic resin and attached to the metallic abutments. After polymerization, the silicone matrix was removed. In the control group, the silica-nylon reinforcement was not applied. Clinically, however, the procedure was similar in all other ways: after preparation of the abutments, the silica-nylon reinforcement was fixed to them, and an impression of the diagnostic waxing filled with bisacrylic resin was positioned on the respective abutments to fabricate the interim restoration.

The experimental silica-nylon reinforcement was presilanized by the manufacturer (Natmar Moldes e Plásticos Ltda) to enhance bonding between the reinforcement material, specifically its glassy component, and the methacrylate contained in the bisacrylic resin. Half of the specimens were subjected to thermal cycling (1000 cycles of 30 seconds each) in water baths between $5^{\circ} \mathrm{C}$ and $55^{\circ} \mathrm{C}$ (ER-37000; ERIOS). The 6 tested groups were as follows: control (no reinforcement), control with thermocycling, addition of reinforcement with extensions in the vertical orientation, addition of reinforcement with extensions in the vertical orientation with thermocycling, addition of reinforcement with extensions in the horizontal orientation, and addition of reinforcement with extensions in the horizontal orientation with thermocycling. Fracture load testing was performed in a universal testing machine (EMIC DL 1000; EMIC). The load was applied with a cylindrical tungsten tip with a 6-mm rounded end to the center point of the interim FPD (Fig. 1) until fracture of the restoration occurred or the maximum load $(895 \mathrm{~N})$ was reached.

The flexural strength of the reinforced bisacrylic resin was tested according to ISO 1567:1999 using $25 \times 10.5 \times 3.3 \mathrm{~mm}$ bars fabricated with a silicone matrix. The 4 groups tested were as follows: control (no reinforcement), control with thermocycling, reinforcement, and reinforcement with thermocycling. A 3-point bending test was performed in a universal testing machine (EMIC DL 1000; EMIC). The bars were positioned on rollers of $3.2 \mathrm{~mm}$ in diameter set $20-\mathrm{mm}$ apart from 


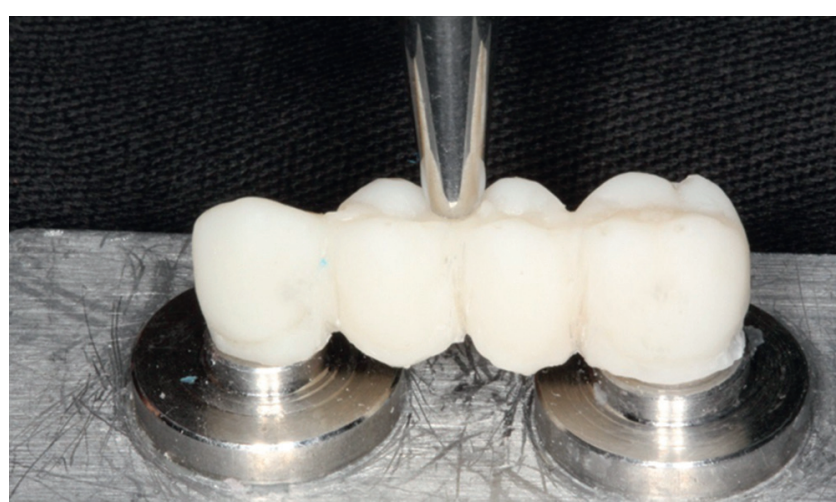

Figure 1. Specimens for fracture test with metallic tip positioned in center of interim fixed dental prosthesis for load application.

Table 1. Mean values $(\mathrm{N})$ and statistical significance of recorded fracture load data

\begin{tabular}{lccc}
\hline & \multicolumn{2}{c}{ Thermocycling } & \\
\cline { 2 - 3 } Reinforcement & Absent (N) & Present (N) & Total (N) \\
\hline Absent & $2.4^{\mathrm{b}}$ & $2.3^{\mathrm{b}}$ & $2.3^{\mathrm{B}}$ \\
\hline Vertical & $2.4^{\mathrm{b}}$ & $2.4^{\mathrm{b}}$ & $2.3^{\mathrm{B}}$ \\
\hline Horizontal & $2.9^{\mathrm{a}}$ & $2.9^{\mathrm{a}}$ & $2.9^{\mathrm{A}}$ \\
\hline Total $(\mathrm{N})$ & $2.5^{\mathrm{A}}$ & $2.5^{\mathrm{A}}$ & - \\
\hline
\end{tabular}

$(P<.001)$

Different superscript lowercase letters indicate statistical difference between groups. Different superscript uppercase letters indicate statistical difference in respective column/row.

each other (span distance), and a third roller applied an increasing load to the top of the specimens until fracture. The flexural strength (FS) (MPa) was calculated according to ISO 1567:1999: $F S=3 F d / 2 w h^{2}$, where $F$ is the fracture load $(\mathrm{N}), d$ is the span distance $(\mathrm{mm})$, and $w$ and $h$ are the width and height of the tested bar ( $\mathrm{mm}$ ).

The fracture load data were transformed into logarithm values and 2-way analysis of variance (ANOVA) was performed to compare all groups regarding "reinforcement presence/orientation" and "thermocycling," followed by the Tukey post hoc test for contrast of the means. A Kaplan-Meier survival analysis was performed to simulate the survival probability of the group with horizontal reinforcement without thermocycling. Flexural strength data were also evaluated by 2-way ANOVA to compare the factors "reinforcement presence" and "thermocycling," followed by the Tukey post hoc test for contrast of the means $(\alpha=.05)$.

\section{RESULTS}

Table 1 displays the mean values (log-transformed data) of the fracture loads of the FPDs. Regarding the 12 initial specimens in the group with horizontal reinforcement without thermocycling, 8 fractured under increasing load application, and the test was suspended for the other 4 specimens after the maximum load was reached $(895 \mathrm{~N})$. The maximum loads reached were included in the statistical analysis. Of the specimens with horizontal

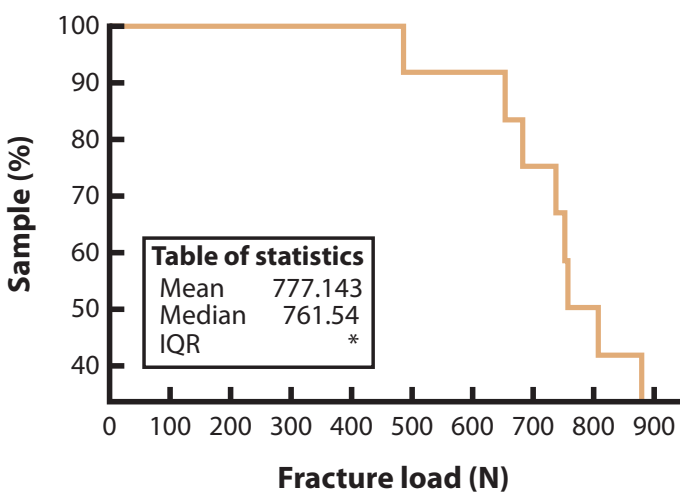

Figure 2. Survival plot for group of prostheses with horizontal reinforcement without thermocycling.

Table 2. Kaplan-Meier estimates for group with horizontal reinforcement without thermocycling

\begin{tabular}{|c|c|c|c|c|c|c|}
\hline \multirow{2}{*}{$\begin{array}{l}\text { Fracture } \\
\text { Load (N) }\end{array}$} & \multirow{2}{*}{$\begin{array}{c}\text { Number at } \\
\text { Risk }\end{array}$} & \multirow{2}{*}{$\begin{array}{l}\text { Number } \\
\text { Failed }\end{array}$} & \multirow{2}{*}{$\begin{array}{c}\text { Survival } \\
\text { Probability }\end{array}$} & \multirow{2}{*}{$\begin{array}{l}\text { Standard } \\
\text { Error }\end{array}$} & \multicolumn{2}{|c|}{$\begin{array}{c}\text { 95\% Normal } \\
\mathrm{Cl}\end{array}$} \\
\hline & & & & & Lower & Upper \\
\hline 487.52 & 12 & 1 & 0.91 & 0.08 & 0.76 & 1.00 \\
\hline 656.24 & 11 & 1 & 0.83 & 0.11 & 0.62 & 1.00 \\
\hline 685.89 & 10 & 1 & 0.75 & 0.12 & 0.50 & 0.99 \\
\hline 741.78 & 9 & 1 & 0.67 & 0.14 & 0.40 & 0.93 \\
\hline 755.71 & 8 & 1 & 0.58 & 0.14 & 0.30 & 0.86 \\
\hline 761.54 & 7 & 1 & 0.50 & 0.14 & 0.22 & 0.78 \\
\hline 811.80 & 6 & 1 & 0.42 & 0.14 & 0.14 & 0.69 \\
\hline 883.19 & 5 & 1 & 0.33 & 0.14 & 0.07 & 0.60 \\
\hline
\end{tabular}

Table 3. Mean values (MPa) and statistical significance of recorded flexural strength data

\begin{tabular}{lccc}
\hline & \multicolumn{2}{c}{ Thermocycling } & \\
\cline { 2 - 3 } Reinforcement & Absent & Present & Total $(\boldsymbol{P}=.001)$ \\
\hline Absent & $1.33(0.1)^{\mathrm{c}}$ & $1.42(0.1)^{\mathrm{C}}$ & $1.38(0.1)^{\mathrm{B}}$ \\
\hline Presence & $1.81(0.1)^{\mathrm{a}}$ & $1.61(0.2)^{\mathrm{b}}$ & $1.71(0.2)^{\mathrm{A}}$ \\
\hline Total $(P=.002)$ & $1.61(0.2)^{\mathrm{A}}$ & $1.47(0.2)^{\mathrm{B}}$ & - \\
\hline
\end{tabular}

Different superscript lowercase letters indicate statistical difference between groups. Different superscript uppercase letters indicate statistical difference in respective column/row.

reinforcement with thermocycling, only 1 specimen fractured below the maximum load. Again, the maximum loads reached were included in the statistical analysis. The experimental reinforcement material used in a horizontal orientation enhanced the maximum fracture loads recorded, from $203 \mathrm{~N}$ to $776 \mathrm{~N}$ in nonthermocycled samples and from $217 \mathrm{~N}$ to $863 \mathrm{~N}$ in thermocycled samples $(P<.001)$ (Table 1$)$. Thermocycling did not affect the fracture load $(P=.679)$.

The survival plot from the Kaplan-Meier analysis of the group with horizontal reinforcement without thermocycling is presented in Figure 2, and the analysis estimates are shown in Table 2. Data (log-transformed values) from the flexural strength tests are presented in Table 3. Both factors (reinforcement and thermocycling) affected flexural strength values $(P=.001$ and $P=.002$, 
respectively). The presence of reinforcement enhanced the values of flexural strength, and, within the reinforced groups, thermocycling reduced flexural strength.

\section{DISCUSSION}

The current study evaluated the effect of incorporating an experimental silica-nylon reinforcement on the fracture load of interim partial fixed dental prostheses (FDPs) and the flexural strength of bars, both made from bisacrylic resin. The tests performed in this study did not simulate a clinical situation, but they did evaluate the efficacy of the experimental reinforcement material under investigation, thus providing an estimate of the clinical performance of this material. Nylon 6.0 enhanced the flexural strength and fracture load of bisacrylic resin, as previously shown for composite resins, ${ }^{15}$ despite the fact that it was applied as a strip in the present study and as a fiber in previous studies. ${ }^{15}$ The single body reinforcement provided by a nylon strip optimizes the stress distribution when loads are applied (unpublished results).

Thermocycling was performed to evaluate degradation of the material tested, with the aim of simulating oral conditions. Half of the specimens were submitted to 1000 cycles of thermal aging. This corresponds to approximately 1 month of clinical function, which is approximately the time that interim prosthetics are used in the oral environment. In previously published reports, materials have been subjected to different numbers of thermocycles, varying from 500 to $12000 .{ }^{10,15-20}$ However, no protocol for the number of cycles to which prosthetic materials should be subjected has been established.

Local load application in the center of FPDs has been used in other studies, regardless of the length of the prothesis. ${ }^{10,15}$ The mean fracture load found in the present study for the nonreinforced specimens $(249.1 \mathrm{~N})$ was higher than that found by Fahmy and Sharawi (95.9 $\mathrm{N})^{10}$; to the best of our knowledge, this is the only previous study that has used a similar methodology. The fracture load reported for bisacrylic-resin interim single crowns $(380 \mathrm{~N})$ is higher than that reported for bisacrylicresin FPDs. ${ }^{21}$ Bisacrylic resin has been investigated in terms of flexural strength, fracture toughness, and combined mechanical properties, but no studies of the fracture load of bisacrylic resin FPDs have been conducted. ${ }^{8,22-26}$ Bisacrylic resin is a reliable material that yields satisfactory results in the tests to which it has been submitted, confirming that it is a good option for the fabrication of interim restorations.

In the current study, the test groups including horizontal reinforcement had the highest values of fracture load (Table 1), regardless of whether they had undergone thermocycling. From the 12 initial specimens in the group with horizontal reinforcement without thermocycling, 8 fractured under increasing load application. The test was suspended for the other 4 specimens after the maximum load was reached (980 N) (Fig. 2). When the maximum load had been reached in these 4 specimens, elastic deformation of the prosthesis was observed. In the group of FPDs with horizontal reinforcement with thermocycling, only 1 specimen fractured before the maximum load was reached. The orientation of the reinforcement was also found to influence flexural strength in a previous study. ${ }^{27}$ If all of the specimens had been tested until fracture in the present study, the fracture load would have been even higher, but the statistical significance of the results would have been similar to those obtained.

In the current study, the flexural strength of the barshaped specimens complemented the results obtained in the fracture load tests, estimating more precisely the stress strength $(\mathrm{MPa})$ that could be supported by the material with or without reinforcement. The mean flexural strength $(27.18 \mathrm{MPa})$ recorded for nonreinforced bars in the present study was lower than that found in other studies. Al Twal and Chadwick ${ }^{24}$ reported a mean flexural strength of $116.5 \mathrm{MPa}$ in a different brand of bisacrylic resin (Protemp 4; 3M ESPE). In the study presented by Kerby et al, ${ }^{23}$ different bisacrylic resins had flexural strengths of $78.9 \mathrm{MPa}$ (Turbo Temp 2; Danville Materials), 85.1 MPa (Integrity; Dentsply Intl), 85.3 MPa (Temphase FastSet; Kerr Corp), and 94.8 MPa (Protemp Plus; 3M ESPE). These results indicate a variation in strength among different brands of the same material. The differences between previous results and the results obtained in the present study may also be explained by differences in the size of the specimens used: specimens of $25 \times 3 \times 2 \mathrm{~mm}$ and $25 \times 2 \times 2 \mathrm{~mm}$ were used in the previously mentioned studies, ${ }^{23,24}$ compared with the specimen size of $25 \times 10.5 \times 3.3 \mathrm{~mm}$ used in this study. With a larger specimen size, there is a higher chance of a critical flaw being introduced into the material, which would lead to premature failure of the material at lower load values. ${ }^{28}$

The silica-nylon reinforcement used in the current study increased the flexural strength of bisacrylic resin bars by $240 \%$ (from 27.18 to $65.93 \mathrm{MPa}$ ). In a previous investigation, the flexural strength of resin was increased by $236 \%$ after glass fiber reinforcement and by $113 \%$ after polyethylene reinforcement. ${ }^{24}$ In the study presented by Hamza et $\mathrm{al}^{22}$ the strength of bisacrylic resin was increased by $114 \%$ and $320 \%$ after reinforcement with glass fiber and polyethylene fiber, respectively. ${ }^{22}$

The loading test used in the present study has also been used in previous studies. ${ }^{10,15}$ Other studies have evaluated the effect of the luting agent used on the fracture load of interim FPDs. However, the present study did not evaluate this factor; this may be considered a limitation. Bonding between the FDP and the abutment 
could enhance the load-bearing capability of the assembly because of improved stress distribution. ${ }^{10,15,16}$

The results of the current study indicate that it is possible to use a silica-nylon reinforcement in 4-unit bisacrylic interim FPDs. The advantages of this reinforcement were enhancement of the fracture load and flexural strength of the material and the simplicity of the technique used for its manufacture.

\section{CONCLUSIONS}

Within the limits of this study, it is possible to conclude that:

1. The addition of the experimental reinforcement positively influenced the fracture load of the proposed model of interim 4-unit FDPs.

2. The orientation of the mesh inside the FDPs influenced the fracture load resistance of the restoration, with a horizontal orientation yielding better resistance results.

3. Thermocycling did not influence the fracture strength of the interim prostheses.

4. Incorporating the experimental reinforcement increased the flexural strength of bisacrylic resin bars. Thermocycling decreased the strength of barshaped specimens.

\section{REFERENCES}

1. Burns DR, Beck DA, Nelson SK. A review of selected dental literature on contemporary provisional fixed prosthodontic treatment: report of the committee on research in fixed prosthodontics of the Academy of Fixed Prosthodontics. J Prosthet Dent 2003;90:474-97.

2. Takamizawa T, Barkmeier W, Tsujimoto A, Scheidel D, Erickson R, Latta M, et al. Mechanical properties and simulated wear of provisional resin materials. Oper Dent 2014; Nov 18. (Epub ahead of print).

3. Haselton DR, Diaz-Arnold AM, Vargas MA. Flexural strength of provisional crown and fixed partial denture resins. J Prosthet Dent 2002;87:225-8.

4. Manak E, Arora A. A Comparative evaluation of temperature changes in the pulpal chamber during direct fabrication of provisional restorations: an in vitro study. I Indian Prosthodont Soc 2011;11:149-55.

5. Uzun G, Keyf F. The effect of fiber reinforcement type and water storage on strength properties of a provisional fixed partial denture resin. J Biomater Appl 2003;17:277-86.

6. Vallittu PK. The effect of void space and polymerization time on transverse strength of acrylic-glass fibre composite. J Oral Rehabil 1995;22:257-61.

7. John J, Gangadhar SA, Shah I. Flexural strength of heat-polymerized polymethyl methacrylate denture resin reinforced with glass, aramid, or nylon fibers. J Prosthet Dent 2001;86(4):424-7.

8. Kim SH, Watts DC. Effect of glass-fiber reinforcement and water storage on fracture toughness (KIC) of polymer-based provisional crown and FPD materials. Int J Prosthodont 2004;17:318-22.
9. Dogan OM, Bolayir G, Keskin S, Dogan A, Bek B. The evaluation of some flexural properties of a denture base resin reinforced with various aesthetic fibers. J Mater Sci Mater Med 2008;19:2343-9.

10. Fahmy NZ, Sharawi A. Effect of two methods of reinforcement on the fracture strength of interim fixed partial dentures. J Prosthodont 2009;18:512-20.

11. Vallittu PK. Comparison of two different silane compounds used for improving adhesion between fibres and acrylic denture base material. J Oral Rehabil 1993;20:533-9.

12. Tian M, Gao Y, Liu Y, Liao $Y, X u$ R, Hedin NE, et al. Bis-GMA/TEGDMA dental composites reinforced with electrospun nylon 6 nanocomposite nanofibers containing highly aligned fibrillar silicate single crystals. Polymer 2007;48:2720-8.

13. Newel J. Essentials of modern materials science and engineering. 1st ed. New Jersey: Wiley; 2009. p. 80-9.

14. Borges ALS, Münchow EA, Souza ACO, Yoshida T, Vallittu PK, Bottino MC. Effect of random/aligned nylon-6/MWCNT fibers on dental resin composite reinforcement. J Mech Behav of Biomed Mat 2015;48:134-44.

15. Vallittu PK. The effect of glass fiber reinforcement on the fracture resistance of a provisional fixed partial denture. J Prosthet Dent 1998;79:125-30.

16. Chen W-C, Hung C-C, Huang Y-C, Wang C-K, Wang J-C. Fracture load of provisional fixed partial dentures with long-span fiber-reinforced acrylic resin and thermocycling. J Dent Sci 2009;4:25-31.

17. Gale MS, Darvell BW. Thermal cycling procedures for laboratory testing of dental restorations. J Dent 1999;27:89-99.

18. Dubois RJ, Kyriakakis P, Weiner S, Vaidyanathan TK. Effects of occlusal loading and thermocycling on the marginal gaps of light-polymerized and autopolymerized resin provisional crowns. J Prosthet Dent 1999;82 161-6.

19. Lang R, Rosentritt M, Behr M, Handel G. Fracture resistance of PMMA and resin matrix composite-based interim FPD materials. Int J Prosthodont 2003; 16:381-4.

20. Meric G, Ruyter IE. Influence of thermal cycling on flexural properties of composites reinforced with unidirectional silica-glass fibers. Dent Mater 2008;24:1050-7.

21. Yilmaz A, Baydas S. Fracture resistance of various temporary crown materials. J Contemp Dent Pract 2007;8:44-51.

22. Hamza TA, Rosenstiel SF, Elhosary MM, Ibraheem RM. The effect of fiber reinforcement on the fracture toughness and flexural strength of provisional restorative resins. J Prosthet Dent 2004:91:258-64.

23. Kerby RE, Knobloch LA, Sharples S, Peregrina A. Mechanical properties of urethane and bis-acryl interim resin materials. J Prosthet Dent 2013;110: 21-8.

24. Al Twal EQ, Chadwick RG. Fibre reinforcement of two temporary composite bridge materials-effect upon flexural properties. J Dent 2012;40:1044-51.

25. Geerts GA, Overturf JH, Oberholzer TG. The effect of different reinforcements on the fracture toughness of materials for interim restorations. J Prosthet Dent 2008;99:461-7.

26. Kamble VD, Parkhedkar RD. In vitro comparative evaluation of the effect of two different fiber reinforcements on the fracture toughness of provisional restorative resins. Indian J Dent Res 2012;23:140-4.

27. Nohrström TJ, Vallittu PK, Yli-Urpo A. The effect of placement and quantity of glass fibers on the fracture resistance of interim fixed partial dentures. Int J Prosthodont 2000;13:72-8.

28. Quinn G. Fractography of ceramics and glasses. Special publication. Maryland: NIST; 20074-1-4-12.

Corresponding author:

Dr Tarcisio José de Arruda Paes-Junior

São Paulo State University (UNESP)

Institute of Science and Technology

Av Eng Francisco José Longo, 777, 12245-000

São Paulo State, São José dos Campo

BRAZIL

Email: tarcisio@fosjc.unesp.br

Copyright (C) 2016 by the Editorial Council for The Journal of Prosthetic Dentistry. 